DOI: $10.17148 /$ IARJSET.2021.8958

\title{
Abrasive water jet Machining experimental investigation and CFD Flow analysis
}

\author{
David Raju kalavakuri ${ }^{1}$, Eshwara Prasad Koorapati ${ }^{2}$ \\ ${ }^{1}$ Research Scholar - Mechanical Engineering, JNTU University, Hyderabad, Telangana \\ ${ }^{2}$ Rtd.Professor - Mechanical Engineering, JNTUH, Hyderabad, Telangana
}

\begin{abstract}
Abrasive Waterjet machining offers the potential for the development of a tool which is less sensitive to material properties, has virtually no thermal effects, and imposes minimal stresses. This method Abrasive water jet machining used industrially in 1983 for cutting of glass. Nowadays, this process is being widely used for machining of hard to machine materials like ceramics, ceramic composites, fiber- reinforced composites, and titanium alloys where conventional machining is often not technically or economically feasible. Different types of abrasives are used in AWJM like garnet, olivine, Aluminum oxide (Al2O3), silica sand, glass bead, silicon carbide (SIC), zirconium, etc. But a survey shows that $90 \%$ of the AWJM is done using garnet as an abrasive. The hardness of the abrasive particles is an important characteristic which strongly influences the cut geometry and that the depth of jet penetration depends strongly on the ratio of the hardness of the target material to the hardness of the abrasive. AWJM involves quite a few parameters that can affect the cutting performance like cutting parameters stand of distance, traverse speed, impact angle and number of passes. Hydraulic parameters like water pressure, orifice diameter, water Jet etc.

The objective of this work is to evaluate and optimize Inlet Pressure of water, Velocity of water, Mass flow rate of water, Mass flow rate of abrasive particles, velocity of water abrasive mixture. Here we need to run analysis on fluid dynamics and flow characteristics using Computational Fluid Dynamics (CFD), which is a science that uses data structures to solve issues of fluid flow like velocity, density, and chemical compositions. Here in CFD analysis we need to run experimental investigation of the general nature of flow through the nozzle and its results in rapid wear of the nozzle which affects the cutting performance.
\end{abstract}

Keywords: Abrasive jet, process parameters, CFD,

\section{INTRODUCTION:}

A schematic layout of AJM is shown in Fig1.The filtered gas supplied under pressure to the mixing chamber containing the abrasive powder and vibrating at 50c/s, entrains the abrasive particle and is the passed into a connecting hose. This abrasive and gas mixture emerges from a small nozzle at high velocity. The abrasive powder federate is controlled by the amplitude of vibration of the mixing chamber. A pressure regulator controls the gas flow and pressure. The nozzle is mounted on a fixture. Either the work piece or the nozzle is moved by cams pantograph or other suitable mechanisms to control the size and shape of the cut. Hand operation is sometimes adequate to remove surface contaminations or in cutting where accuracy is not very critical. Dust removal equipmentis necessary to protect the environment.

In AWJM applications, the absence of thermal distortion is achieved due to its cold cutting process since the material temperature will not exceed $70{ }^{\circ} \mathrm{C}$ and AWJM is also considered environmentally friendly and sustainable as it does not omit any hazardous vapor. Sustainable manufacturing aims to achieve an efficient operation at the same time, reducing the environmental effect. Recycling and reusing these abrasives make AWJM more economical, effective, and environmentally friendly. The discussed competitive advantages of AWJM have been the rational reason behind its expanding utilization and continuous progression.

Carbon filaments or fibers which are generally used to decrease the heaviness of primary parts on the airplane bring about further developed efficiency, diminished emanations, and expanded burden conveying limit of the airplane. CFRP likewise discovered application in vehicle parts like vehicle body, outline, hood, rooftop, and body board for transport, propeller shaft, packed flammable gas tank, radiator center. 
DOI: $10.17148 / I A R J S E T .2021 .8958$

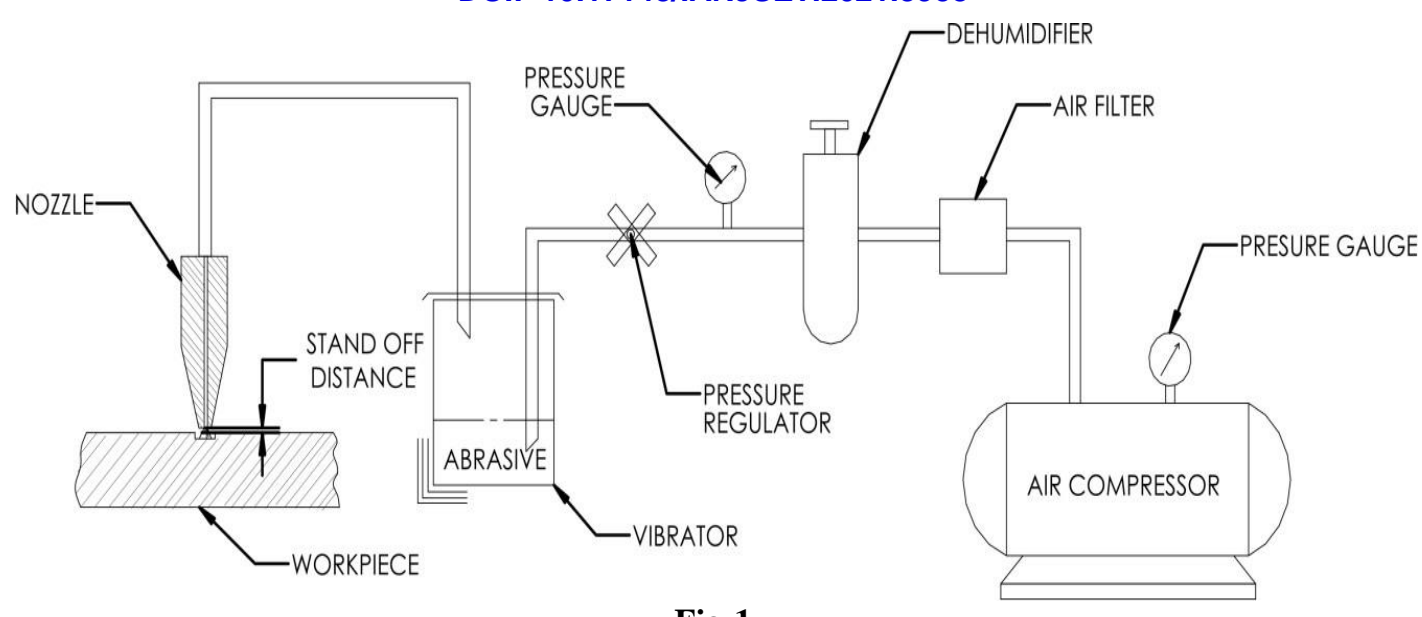

Fig-1

\section{LITERATURE REVIEW}

T. Matsumura [1], inspected the stagnation impact amid Abrasive water stream machining of Glass. The procedure is related with disintegration, in which the surface profiles changes with miss happening, break and material evacuation at collision of the particles. Disintegration can be controlled by the sizes, the speeds, and the impingement points of the strong particles.

Rodovan Kovacevic [2] examined that, with a specific end goal to control the uniformity of AWJM infiltration into the work piece, it is important to devise an observing philosophy that can by implication screen the profundity of rough water fly entrance. It was demonstrated that the work piece nominal compel produced by a rough water stream could be utilized as the pointer of the profundity of entrance, and that a coercively feedback control holds guarantee as a viable method to direct the profundity of fly infiltration.

Ramachandran.N [3] watched that in rough water fly machining, yet numerous parameters are to be characterized, since investigative work on the impacts of the molecule circulation in the water-grating blend stream, of the speed appropriation of these particles and of this mix, on the material evacuation rate, etc.

Bhattacharya [4] contemplated the impact of rough stream rate (AFR) and remain off-separate on the material expulsion rate (MRR). They watched that material expulsion rate achieves an ideal incentive with the expansion in grating stream rate and Stand-off-separation, and after that falls with additionally increment in these parameters.

Wang and Wong [5] made to broke down that as the abrasive particles move down the fly, they free their motor vitality and the relative quality zone of the fly is limited. Thus, the width of cut at the base of the opening is littler than that at the best.

Mehul.A.Raval, Chirag. P. Patel[6] has performed experimentation on Abrasive water stream machine parameter advancement on Steel material by utilizing Design of ExperimentTaguchi orthogonal Array L9, and additionally Gray Relation Analysis system to get decision about at what machine parameters the procedure is ideal and effective. They have taken controllable factors, in particular, rough grain estimate, weight, tip separate, post remove. Furthermore, they likewise discovered that attractive Abrasive in water stream machining is practical contrasting option to aluminum oxide and different abrasives.

M.SreenivasaRao, S.Ravinder and A. Seshu Kumar[7]conducted the trials on gentle steel material by utilizing control parameters in three levels, to discover ideal surface harshness and which parameter having most huge impact at first glance unpleasantness. Creators have utilized ANOVA and F test and S/N proportion strategies to finish the experiment.The conclusion they got is Traverse Speed is the most huge view point on Surface harshness amidst Abrasive water fly machining and The complimented parametric blend for ideal surface unpleasantness.

Mahesh et al. [8] endeavored Fuzzy Modeling with GA to upgrade the MRR by appropriate choice of process parameter in AWJM. They demonstrated the procedure parameters utilizing fluffy with test informational index to anticipate profundity of cut, at that point it is inserted to GA to expand the MRR.

Zohourkari et al., [9] researched the impact of process parameters on MRR for AWJ turning. A five-level focal composite rotatable exploratory plan (CCRD) is utilized to discover the impacts of parameters and their association is dissected with ANOVA.

Nanduri et al. [10] studied the phenomenon of nozzle wear in the abrasive water jet environment. The effect of nozzle geometry such as bore eccentricity, nozzle length, inlet depth; inlet angle and nozzle diameters on wear have been investigated. 


\section{DOI: 10.17148/IARJSET.2021.8958}

Hloch et al. [11] discussed the analysis of vibrations generated during the AWJ machining of AISI309 with frequency spectrum. Controlled factor involved in experiment was abrasive mass flow rate with values 250 and $400 \mathrm{~g} /$ with constant rate of speed $100 \mathrm{~mm} / \mathrm{min}$.

Hreha et al. [12] studied the causes of arising vibration and acoustic emission, course of vibration and acoustic emission in AWJM using frequency spectrum. Data were collected by touch sensors within controlled experiment, in which the AWJ technology for cutting alloy steel was used. During the experiments, some input factors were changed and measured parameters were subjected to different types of analysis using specialized software. Obtained data provide information about vibration and acoustic emission spectrum and enable us to find a dependency between the surface topography of cut materials and the emission spectrum of the accompanying physical phenomena arising during the AWJ process.

P. Venkateswarreddy et al [13] presented the work in set to ascertain experimentally the influence of three input parameters on the three responses mentioned above through ANOVA. WASPAS and MOORA are two powerful techniques that are used for multi-objective optimization, and the ranks of both the MCDM methods were observed to be same. Traverse speed and abrasive mass flow rate are proven to be statistically significant on MRR and surface finish, whereas standoff distance along with the above two parameters is also significant on the response kerf width. Machined surface morphology is studied using scanning electron microscopy.

M. Rajyalakshmi et al [14] presented a paper and attempt is made to review the research work carried out so far in the area of AWJM.Discussed about various statistical and modern approaches are applied to optimize these process parameters to improve the performance characteristics. But most of the authors considered common process parameters like hydraulic pressure, traverse speed, stand-off distance and abrasive flow rate. Other parameters can also be considered for optimization, which influence the quality parameters.

\section{Experimental Set up}

The experiments were performed on S-3015 AWJM CNC machine, manufactured by Water Jet Germany Private Limited. Water jet cutting uses high pressure water to cut softer material like rubber and abrasive jets adds abrasive to water to cut harder material like steel, glass and titanium. The high pressure water is forced through a tiny orifice to concentrate high energy in a tiny area to cut since this process is neither chemical and nor thermal, therefore it does not cause any change in physical and metallurgical properties of the work piece. Maximum Speed : $4572 \mathrm{~mm} / \mathrm{min}$, maximum operating pressure: $500 \mathrm{MPa}$, repeatability accuracy: $\pm 0.025 \mathrm{~mm}$ ) was used for experimentation.

\section{NOZZLE}

AJM nozzle is usually made of tungsten carbide or sapphire (usually life - 300 hours for sapphire, 20 to 30 hours for WC) which has resistance to wear. The nozzle is made of either circular or rectangular cross section and head can be head can be straight, or at a right angle. It is so designed that loss of pressure due to the bends, friction etc. is minimum possible. In integration manufacturing technology abrasive jet finishing combined with grinding gives rise to a precision finishing process, in which slurry of abrasive and liquid solvent is introduced to grinding area between wheel and work surface under no radial feed. The study of the results of machining under various operating conditions approves that a commercial AJM machine was used, with nozzles hiving diameter ranging from 0.45 to $0.65 \mathrm{~mm}$, the nozzle materials being either tungsten carbide or sapphire, which have high tool lives. SIC and aluminum oxides were the two abrasives used. Other parameters studied were standoff distance $(5-10 \mathrm{~mm})$, spray angles $\left(60^{\circ}\right.$ and $\left.90^{\circ}\right)$ and pressures ( 5 and 7 bars) for materials like ceramics, glass. The abrasive used was garnet of mesh size 80 . The variables were stand-off distance (SOD) of the nozzle from the work piece surface; feed rate and jet pressure. The evaluating criteria width of cut, taper of the cut slot and work surface roughness. It was found that in order to reduce the width of cut; the nozzle should be placed close to the work piece surface. Increase in jet pressure effects in widening of the cut both at the top and at exit of the jet from the work piece distance as variable and Abrasive grit size, Nozzle diameter and shape of abrasive as constant. And the outputs found are MRR, Ra and KERF. Further grey relation analysis is applied for finding optimal parameters. The nozzle assembly is shown in fig 2 and mesh anlysis in fig no3 
DOI: $10.17148 /$ IARJSET.2021.8958

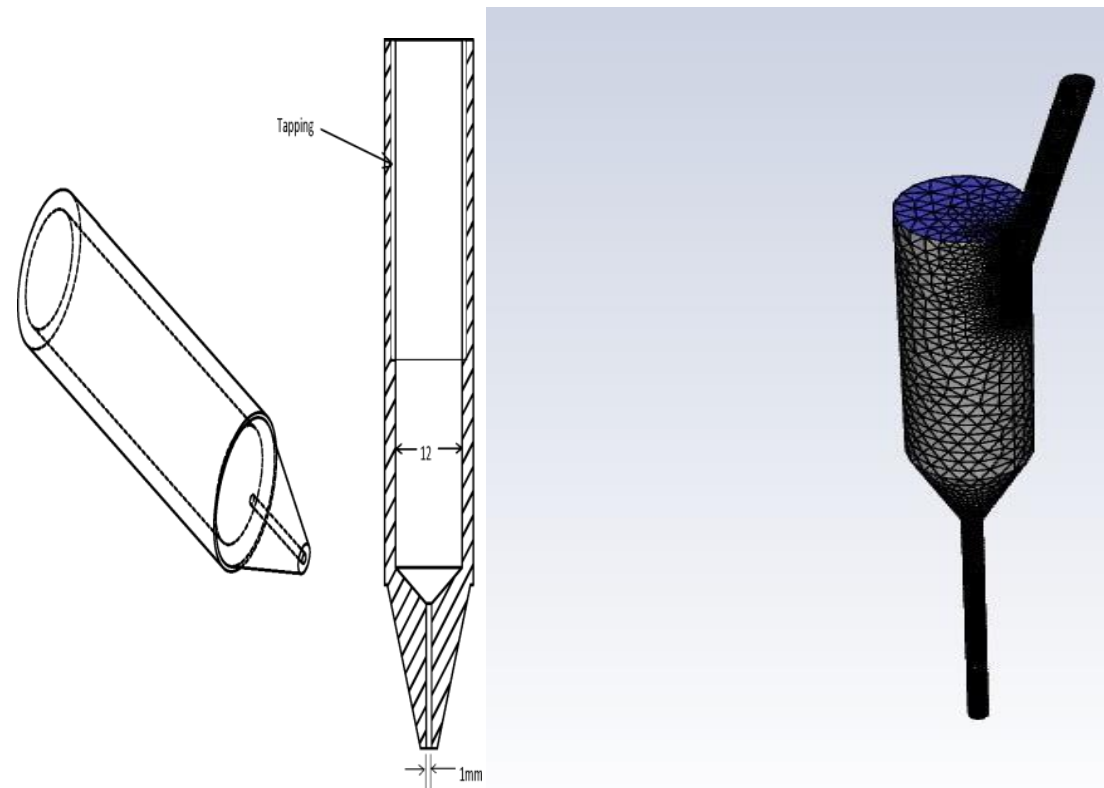

Fig 2 Fig no.3 Mesh analysis of Nozzle

Before lattice the model and even before building the model, it is essential to consider whether a free work or a mapped cross section is proper for the examination. A free work has no limitations as far as component shapes and has no predefined example connected to it. Contrast with a free work, a mapped cross section is confined as long as the component shape it contains and the pattern of mesh. Mapped area mesh contains either quadrilateral or just triangular components, while a mapped volume cross section contains just hexahedron components. In the event that we need this kind of lattice, we must form the geometry as arrangement of genuinely normal volumes and/or regions that can acknowledge a mapped network.

\section{RESULTS:}

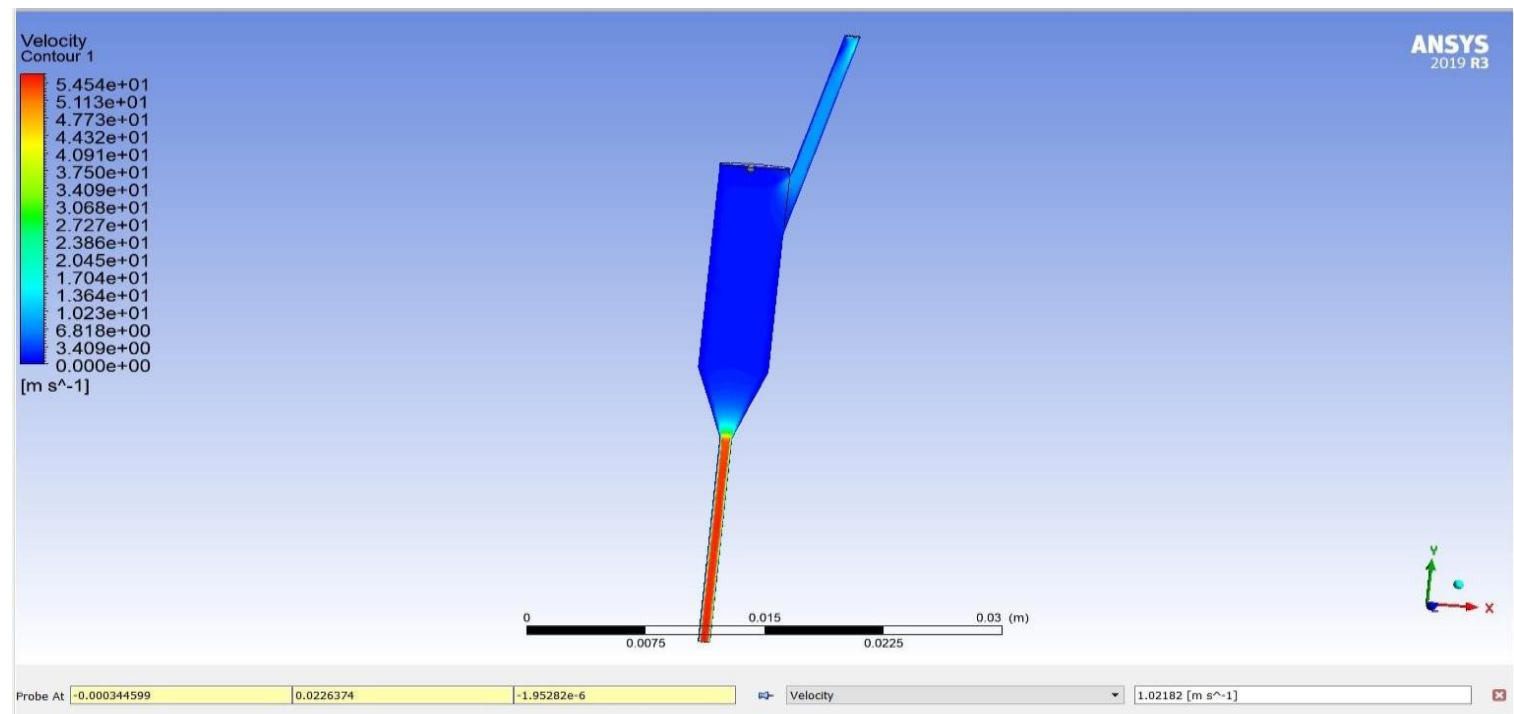

Fig no.4 Velocity at water inlet 
International Advanced Research Journal in Science, Engineering and Technology

Vol. 8, Issue 9, September 2021

DOI: $10.17148 / I A R J S E T .2021 .8958$

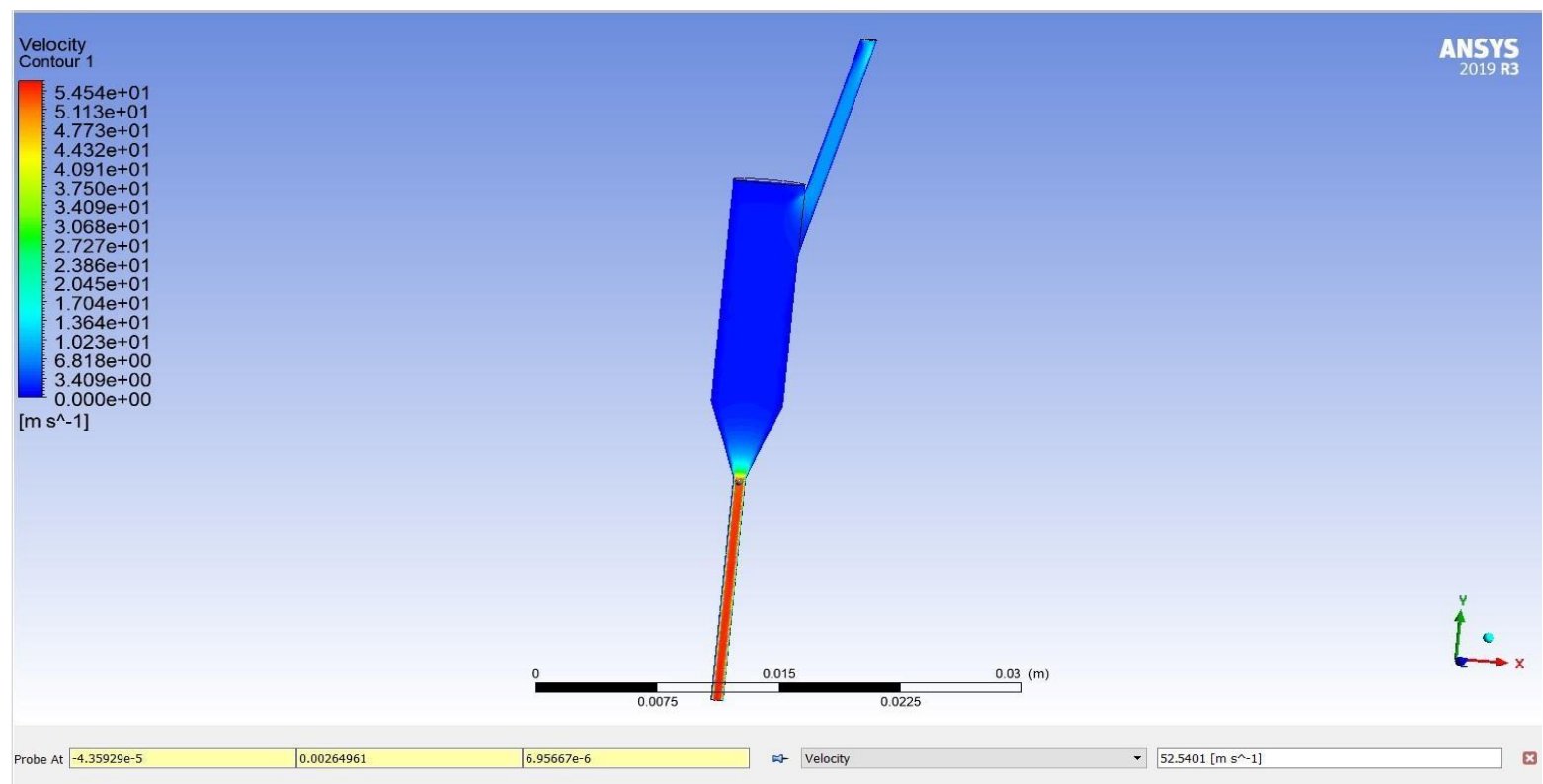

Fig no.5 Velocity at outlet

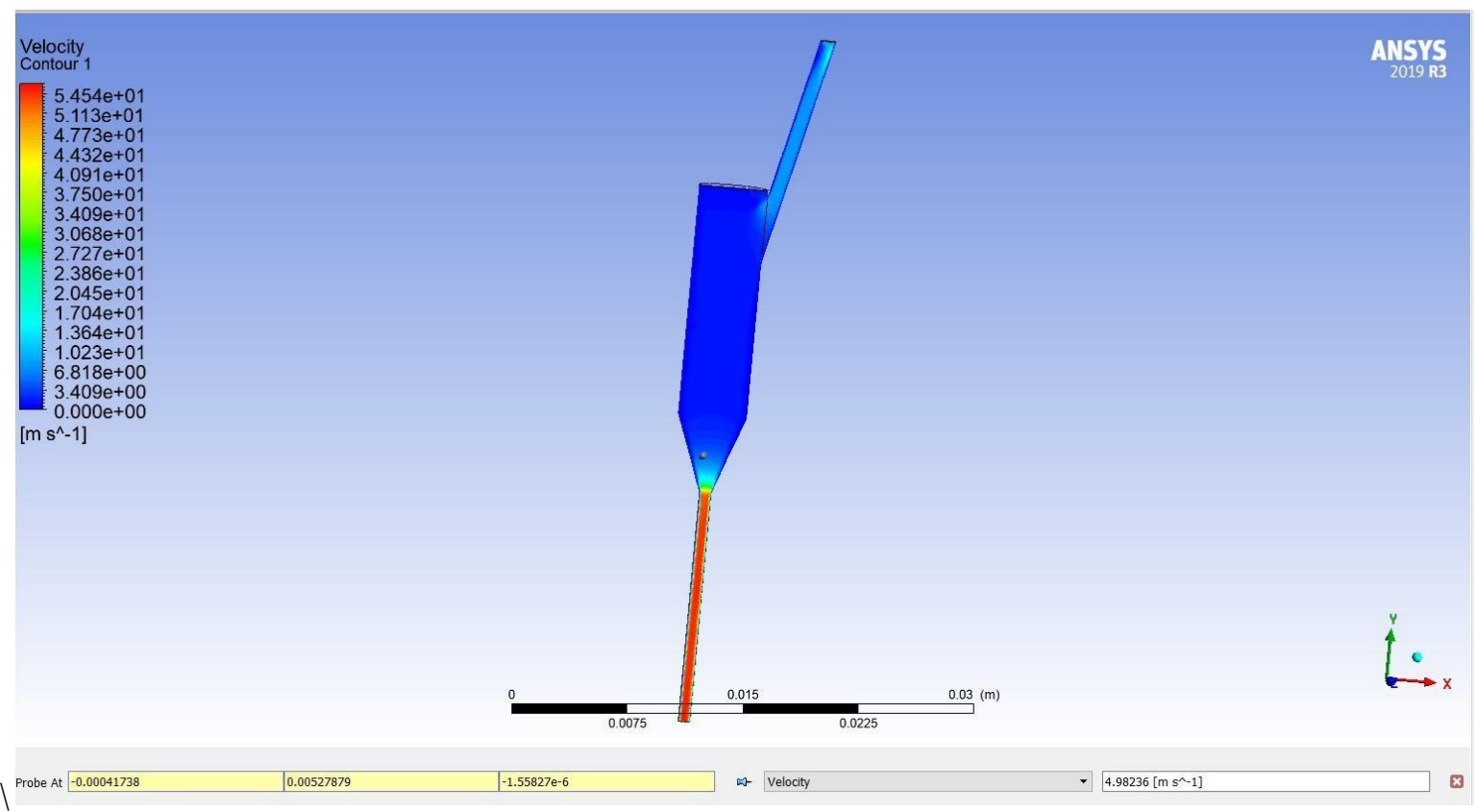

Fig no.6 Velocity at mixing chamber 
International Advanced Research Journal in Science, Engineering and Technology

Vol. 8, Issue 9, September 2021

DOI: 10.17148/IARJSET.2021.8958

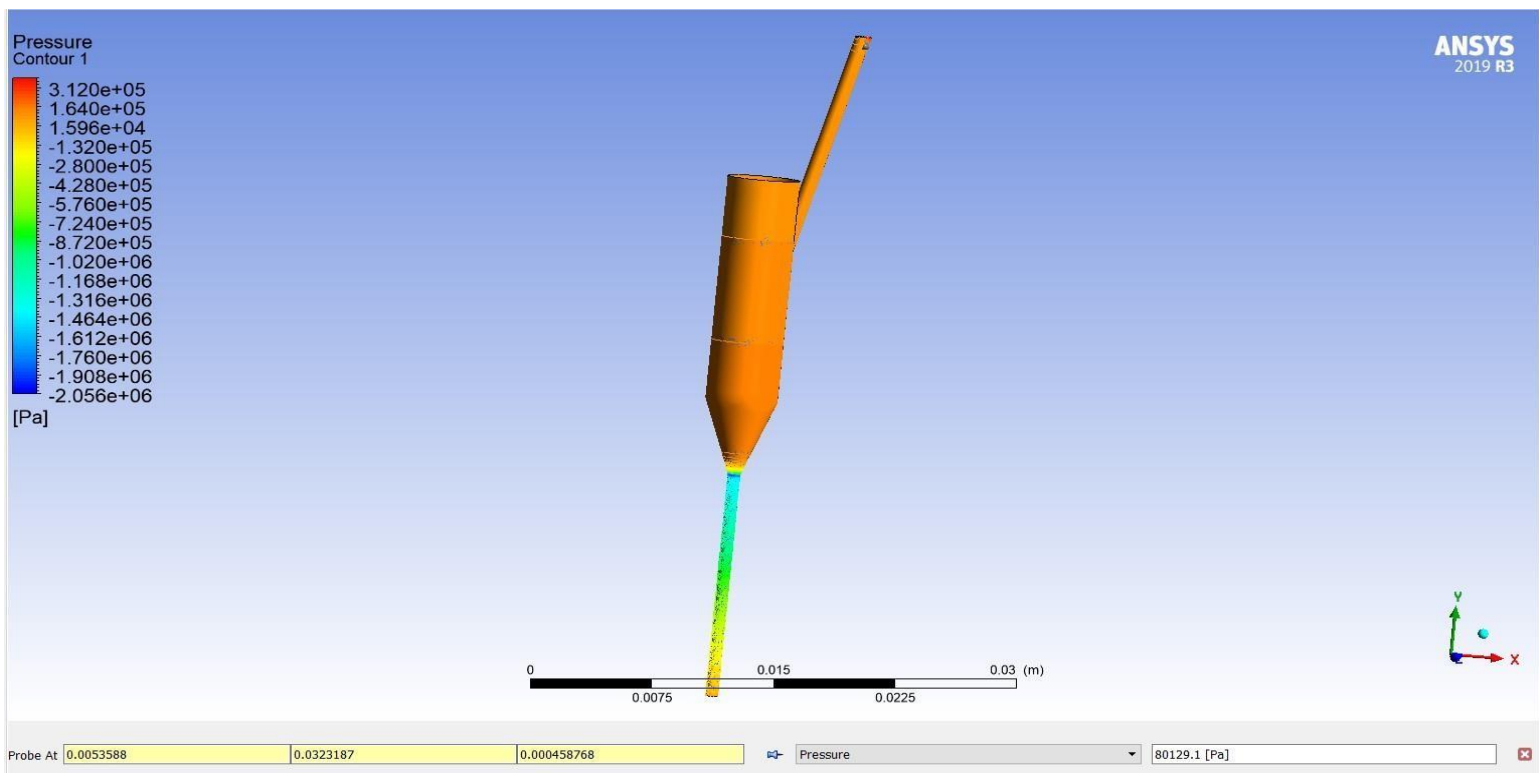

Fig no.7 Pressure at abrasive inlet

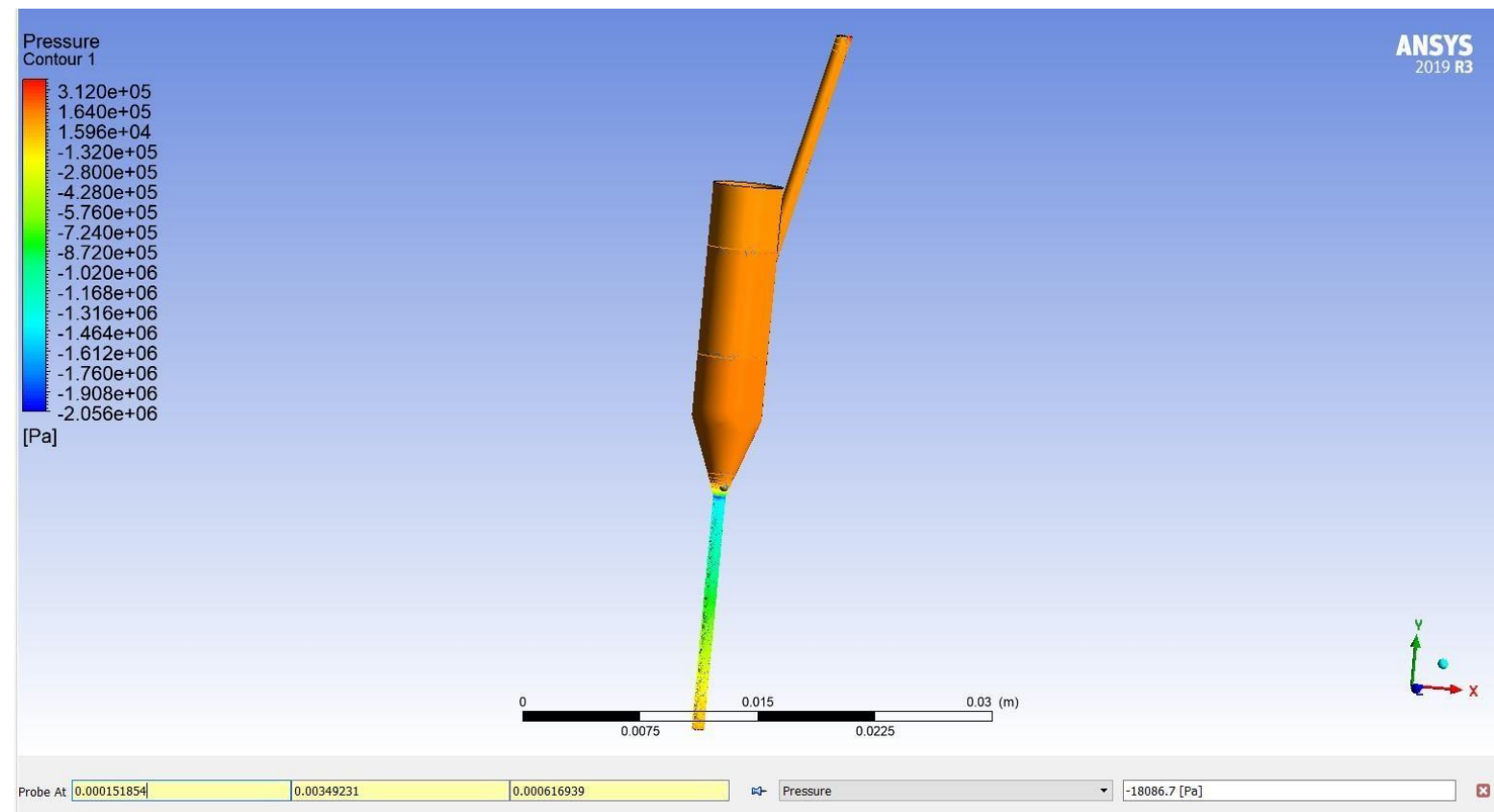

Fig no.8 Pressure at outlet 
International Advanced Research Journal in Science, Engineering and Technology

Vol. 8, Issue 9, September 2021

DOI: 10.17148/IARJSET.2021.8958

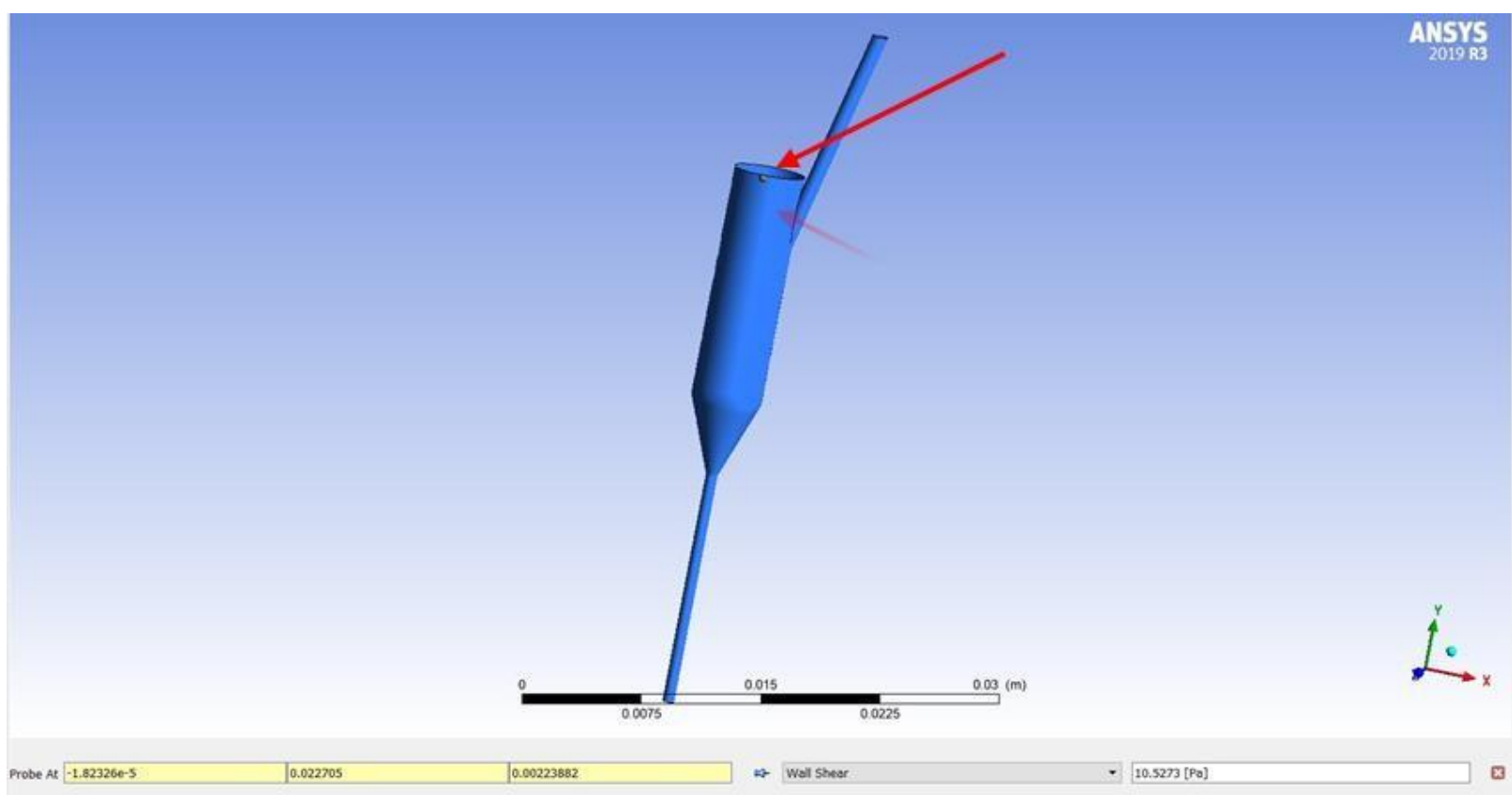

Fig no.9 Wall shear at inlet

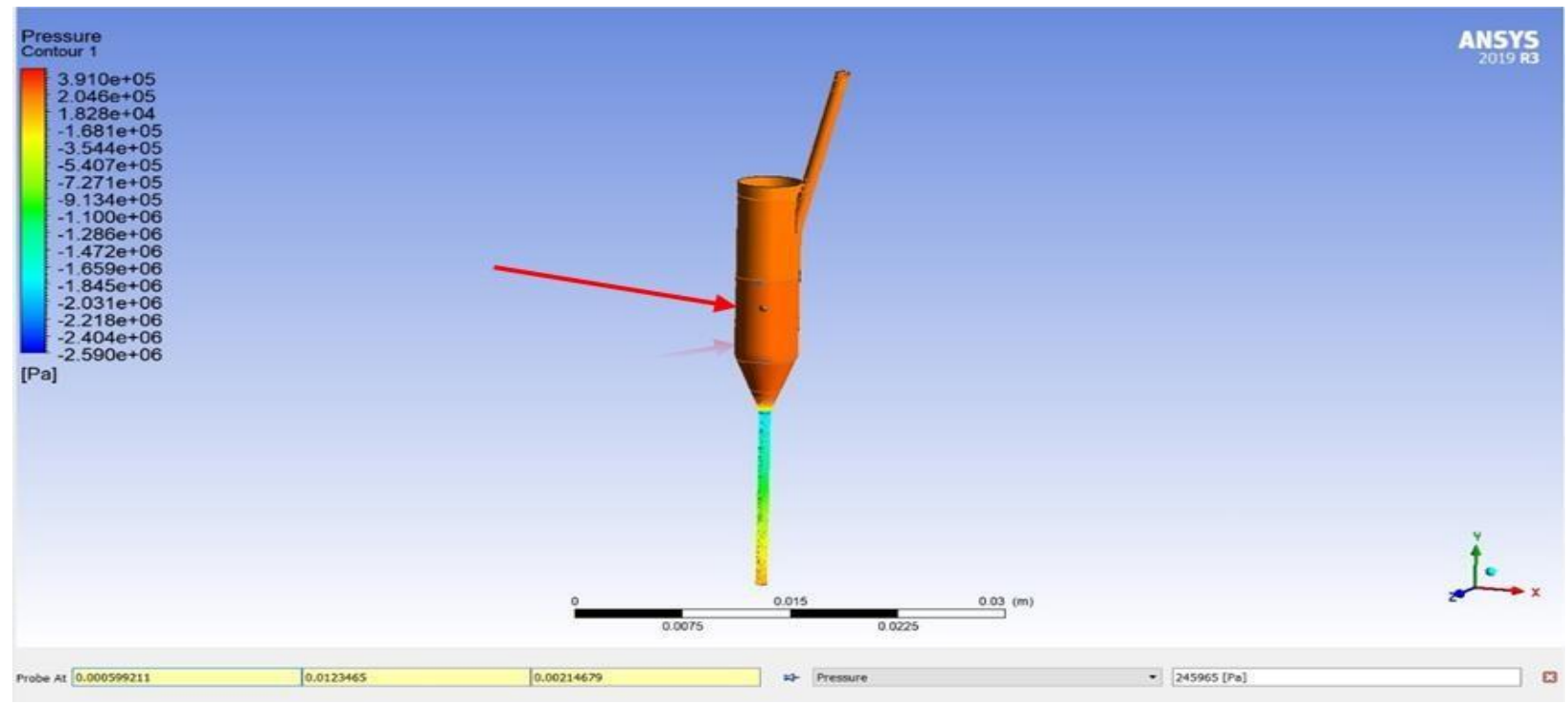

Fig no.10 Mixing chamber pressure 


\section{RESULTS AND FUTURE SCOPE OF WORK:}

The experimentation investigation and optimization of process parameters of AWJM is done and obtained by CFD analysis using ANSYS software. The variations in the flow is obtained in the process parameters of AWJM.

\begin{tabular}{|c|c|c|c|c|c|c|c|c|c|c|c|}
\hline $\begin{array}{l}\text { si } \\
\text { no }\end{array}$ & $\begin{array}{l}\text { Tota } \\
\text { l } \\
\text { guag } \\
\text { e } \\
\text { pres } \\
\text { sure } \\
\text { (pa) }\end{array}$ & $\begin{array}{l}\text { Mass } \\
\text { flow } \\
\text { rate(k } \\
\text { g/sec) }\end{array}$ & $\begin{array}{l}\text { Water } \\
\text { inlet } \\
\text { pressu } \\
\text { re(Pa) }\end{array}$ & $\begin{array}{l}\text { Abras } \\
\text { ive } \\
\text { inlet } \\
\text { pressu } \\
\text { re(Pa) }\end{array}$ & $\begin{array}{l}\text { Pressu } \\
\text { re at } \\
\text { mixing } \\
\text { chamb } \\
\text { er }\end{array}$ & $\begin{array}{l}\text { Water } \\
\text { Outlet } \\
\text { pressu } \\
\text { re(Pa) }\end{array}$ & $\begin{array}{l}\text { Veloci } \\
\text { ty at } \\
\text { Inlet( } \\
\mathrm{m} / \mathbf{s})\end{array}$ & $\begin{array}{l}\text { Veloci } \\
\text { ty } \\
\text { before } \\
\text { exit } \\
(\mathrm{m} / \mathrm{s})\end{array}$ & $\begin{array}{l}\text { Veloc } \\
\text { ity } \\
\text { exit } \\
(\mathrm{m} / \mathrm{s})\end{array}$ & $\begin{array}{l}\text { Wall } \\
\text { shear } \\
\text { at } \\
\text { Inlet } \\
\text { (pa) }\end{array}$ & $\begin{array}{l}\text { Wall } \\
\text { shear } \\
\text { at out } \\
\text { let } \\
\text { (pa) }\end{array}$ \\
\hline 1 & 100 & $\begin{array}{l}0.004 \\
2\end{array}$ & 100.4 & 80.13 & $\begin{array}{l}137.50 \\
5\end{array}$ & 18.09 & 1.0218 & 4.9823 & 52.54 & 9.6015 & 83.555 \\
\hline 2 & 150 & $\begin{array}{l}0.004 \\
2\end{array}$ & 150.4 & 130.7 & $\begin{array}{l}191.96 \\
8\end{array}$ & 11.81 & 1.1223 & 5.3249 & 55.93 & 10.527 & 88.984 \\
\hline 3 & 200 & $\begin{array}{l}0.004 \\
2\end{array}$ & 200.4 & 182.5 & $\begin{array}{l}245.96 \\
5\end{array}$ & 44.64 & 1.2089 & 5.6063 & 58.94 & 11.636 & 93.741 \\
\hline
\end{tabular}

Water is pressurized up to $400 \mathrm{Mpa}$ and expelled through a sapphire nozzle to form a coherent high-velocity jet. Abrasives are added into a specially shaped abrasive-jet nozzle from separate feed ports. Few researchers were concerned with cutting forces and temperature. This may be attributed to the fact that AWJM is a cold cutting process and cutting forces are very low. No literature available so far for multi response optimization of process variables and more work is required to be done in this area.

\section{REFERENCES}

1. Matsumura, T., T. Muramatsu, and S. Fueki. "Abrasive water jet machining of glass with stagnation effect."CIRP Annals-Manufacturing Technology 60, no. 1 (2011): $355-358$.

2. Momber, A., Kovacevic, R. “Principles of Abrasive Waterjet Machining”. Springer-Verlag, London, 1998.

3. Ramachandran.N, Pandey.S.S and Ramakrishnan.N "The role of deburring in manufacturing- a state of art review" Jl. Of material processing technology, V44, steps to robust design" Prentice-Hall Pvt Ltd, New Delhi (1993).

4. B.; Bhattacharyya, B. et al. Analysis on profile accuracy for ultrasonic machining of alumina ceramics. The International Journal of Advanced Manufacturing Technology, 2013, 67(5-8): 1683-1691.

5. Wang, J. \& Wong, W.C.K. 1999. A Study of Waterjet Cutting of Metallic Coated Sheet Steels, International Journal of Machine Tools and Manufacture, 39, pp. 855-870.

6. Mehul.A.Raval, Chirag. P. Patel "Parametric Optimization of Magnetic Abrasive Water Jet Machining of AISI 52100 Steel Using Grey Relational Analysis" / International Journal of Engineering Research and Applications (IJERA) ISSN: 2248-9622 www.ijera.com Vol. 3, Issue 4, pp. 527-530,May-Jun (2013)

7. M.SreenivasaRao, S.Ravinder and A. Seshu Kumar "Parametric Optimization of Abrasive Waterjet Machining for Mild Steel Touchy Approach "International Journal of Current Engineering and Technology, Special Issue-2 (Feb 2014)

8. Mahesh Todkar, and Jyoti Patkure, "Fuzzy Modeling And GA Optimization for Optimal Selection of Process Parameters to Maximize MRR in Abrasive Water Jet Machining", International Journal on Theoretical and Applied Research in Mechanical Engineering, 2014, Vol. 3, Issue 1, pp 9-16.

9. Imam Zohourkari, Mehdi Zohoor, and Massimiliano Annoni, "Investigation of the Effects of Machining Parameters on Material Removal Rate in Abrasive Waterjet Turning", Advances in Mechanical Engineering, 2014, Vol. 2014, pp 1-11.

10. Madhusarathi Nanduri, David G. Taggart and Thomas J. Kim, "The effects of system and geometric parameters on abrasive Waterjet nozzle wear" Journal of Machine Tools and Manufacture, 2002, Volume 42, pp 615-623.

11. Sergej HLOCH, Vincent PERZEL, Pavol HREHA, Hakan TOZAN and Jan VALICEK, "Vibration as A Source of Information for Abrasive Waterjet Monitoring”, Journal of Naval Science and Engineering,2011, Vol.7 , No.1, pp. 71-85,International Journal of Machine Tools and Manufacture, 2002, Volume 42, pp 615-623.

12. PavolHreha, Sergej Hloch and Vincent Petrel, “Analysis of Acoustic Emission Recorded During Monitoring of Abrasive Waterjet Cutting of Stainless steel AISI 309”,Tehnički vjesnik, 2012, Vol 19, pp 355-359.

13. Venkateshwar Reddy, P., Suresh Kumar, G. \& Satish Kumar, V (2020). Multi-response Optimization in Machining Inconel-625 by Abrasive Water Jet Machining Process Using WASPAS and MOORA. Arab J Sci Eng 45, 9843-9857 (2020). https://doi.org/10.1007/s13369-02004959-9.

14. M. Rajyalakshmi P. Suresh (2016) Abrasive Water Jet Machining - A Review onCurrent Development, IJSTE - International Journal of Science Technology \& Engineering | Volume 2 | Issue 12 | June 2016 ISSN (online): 2349-784X, Page 428-434

15. Dhineshbabu V.; Aswin K. A; Bharath Prithivi B.; Dhanush Kumar P.. "Design and Fabrication of Industry Based Hydraulic Manifold Using Additive Manufacturing". International Research Journal on Advanced Science Hub, 3, Special Issue ICIES-2021 4S, 2021, 34-41. doi: 10.47392/irjash.2021.107

16. Karthikeyan A G; Pradeep V P; Maruthapandian .. "Optimization of Multiple Input Process Parameters of WEDM on Titanium Ti 6Al-4v (Grade 5) By Taguchi Analysis". International Research Journal on Advanced Science Hub, 2, 6, 2020, 1-10. doi: 10.47392/irjash.2020.29 